\title{
An Introduction to IPR as a Participatory Design Research Method
}

\section{Sarah Kettley}

Nottingham Trent University

Nottingham, NG1 4BU, UK

sarah.kettley@ntu.ac.uk

\section{Richard Kettley}

Nottingham Trent University

Nottingham, NG1 4BU, UK

richard.kettley@ntu.ac.uk

\section{Matthew Bates}

Nottingham Trent University

Nottingham, NG1 4BU, UK

matthew.bates@ntu.ac.uk
Permission to make digital or hard copies of all or part of this work for personal or classroom use is granted without fee provided that copies are not made or distributed for profit or commercial advantage and that copies bear this notice and the full citation on the first page. Copyrights for components of this work owned by others than ACM must be honored. Abstracting with credit is permitted. To copy otherwise, or republish, to post on servers or to redistribute to lists, requires prior specific permission and/or a fee. Request permissions from Permissions@acm.org.

Ubicomp/ISWC'15 Adjunct, September 07-11, 2015, Osaka, Japan (C) 2015 ACM. ISBN 978-1-4503-3575-1/15/09 ..\$15.00 DOI: http://dx.doi.org/10.1145/2800835.2807944

\section{Abstract}

This paper outlines the method of Interpersonal Process Recall (IPR) as a Participatory Design method,

especially in the context of design for mental health and wellbeing. IPR is more commonly used in

psychotherapy and other helping professions to help trainees and practitioners and their clients reflect on their process, using AV recordings of interactions for the facilitation of deep and accurate recall. We propose that it can provide a mechanism for reflection on team working and relational aspects of Participatory Design. The paper discusses the rationale for using IPR and the ways in which the method relate to phenomenological inquiry (including the Person-Centred Approach); it describes an IPR research method protocol, and finishes with a discussion of the implications for Participatory Design methodologies.

\section{Author Keywords}

Reflection; Participatory Design; team working; wellbeing; phenomenological methods; ethics.

\section{ACM Classification Keywords}

J.4 [Social And Behavioral Sciences]: Psychology; K.4.1 [Public Policy Issues]: Ethics. 


\section{Introduction}

Recent calls for reflexivity in HCI [33] have pointed out the need for design researchers to be explicitly reflexive in their practice when working with participants; others point out that this need is intensified when members of design research teams come from different disciplinary backgrounds, and have different mindsets and expectations [28]. Reflection is needed not only to enable a healthy researcherparticipant relationship, but to support individual researchers as they are challenged by the process [12] [22]; we need to reflect both on the user experience of participatory design, and on the design team experience.

The Interpersonal Process Recall (IPR) method has been used in fields such as social work [18] and education [29] as well as therapeutic practices [1], [2]. In IPR, interaction is audio-video captured which is then replayed to the participant(s) who are encouraged to reflect verbally on what they were feeling, thinking and experiencing at any given moment. IPR consists of two roles: an 'inquirer' and a 'recaller' (or recallers). The next section of the paper draws on the therapeutic training and research practice of the second author [14].

\section{What is IPR?}

In this paper we will describe what IPR is, offer a rationale for its use, suggest its philosophical congruence with phenomenological and person-centred approaches, and give an example of how IPR might be 'done'. We will then explore the implications for its use in participatory design research.

An IPR interview may start like this:
"IPR is about learning though discovery; it is an opportunity to think about the original experience more fully than there was time to do then:

- This is because we think and feel faster than can be put into words

- There might not have been time to say everything

- Perhaps there were things you chose not to say

- You might have experienced vague feelings and couldn't find the words in the moment to express them or time moved on before you had a chance to pay them full attention

- You might have had impressions of the other person and guesses about the other person's impressions of you

- Images may have sprung to mind, you may have been aware of bodily reactions, ideas and feelings that remained unspoken

The purpose is to recall and explore.

Please pause the video whenever you remember anything beyond what shows. It doesn't have to seem important, just say anything that comes to mind. Stop the recording as often as you can. Remember you are in charge and keep your hand on the switch so you can stop it the moment you recall anything. Over to you!" ([14] adapted from [4]).

IPR is a process which invites the holistic self-directed self-exploration of the participant, leading to selfdiscovery, which might then be used as a springboard for reflexivity. 
A typical encounter might be described in this way (Jane Allen-Brown, of the former British IPR Association, personal communication):

- An interaction of two or more people is video or audio recorded

- The recording is played, by the recaller/s, to a colleague who takes on the role of inquirer

- The recaller has control of the playback, pausing it whenever they choose for their own comment

- The inquirer may offer prompts, but the learning is the recaller's and the inquirer has no interest other than to facilitate the recaller's self-learning

- At the end of the recall session, there is a debrief, in which the recaller reflects on the material that has been brought up, and any research questions may be explored

In the research context, the recording of the original transaction may now be destroyed as it is the recall (and subsequent reflections) that forms the data (Cooke, Oldale, course leader and tutor, Sherwood Psychotherapy Training Institiute, Nottingham, personal communication).

\section{Rationale for Using IPR}

The usefulness of IPR is based on the notion that "at any moment in time we are having a multitude of thoughts, feelings, sensations, of which we are not normally aware, nor have time to process, but which subtly affect the way we behave, react and interact" [1:154-5].

Therefore there are a number of factors that facilitate safe, open expression of these processes:
- Looking/listening to a tape gives some distance

- As a past interaction, the outcome is already known

- There is time to slow down and reflect on the events and experiences

- The inquirer offers structure and support without controlling the level of exploration

- Finding words for difficult feelings and experiences tends to reduce their fearsomeness

- It provides opportunities to rehearse saying difficult or frightening things

- It serves as a witness to the externalised thoughts

- It may reset power relations towards greater equality in mutual or group recall (training material developed by Peter Clarke of the former British IPR Association, based on Kagan [13])

The guiding principle that 'the individual knows better than anyone else the meaning an experience had for him or her' [13:203] is fundamentally respectful and empowering of the individual, making this a particularly suitable and productive method for discovering the subjective experience of all individuals, including those that are potentially vulnerable and hard to reach.

\section{The philosophical congruence of IPR with phenomenological and person-centred}

\section{approaches}

In this section we explore the philosophical congruence of qualitative research and phenomenological methodology with the Person-Centred Approach, as well as the appropriateness of Interpersonal Process Recall as a data collection method. In supervision, IPR is recognised as a method for deepening the practitioner's awareness of interpersonal processes and 
for fostering reflexivity. We suggest it is equally useful and valuable when used as part of research: "it does seem that this non-judgemental and value-free way of using a tape of the original interaction to kick-start a memory has the effect of triggering and activating a fairly accurate memory that is richer, more detailed and more plausible than most other ways of reporting a past event" [1:163].

The non-judgemental stance of the Inquirer in IPR implies a prizing of the Recaller that resonates with the condition of Unconditional Positive Regard (UPR), which is central to the Person-Centred Approach (PCA) [25]. Equally the focus on the Inquirer as facilitator of the Recaller's self-discovery rather than interpreter of the content, is consistent with the power dynamic established by adopting an attitude of UPR, or valuing of the individual.

IPR focuses on the self-learning of the Recaller - the co-researcher or participant - and views the role of Inquirer - the researcher - as primarily a facilitator: "Self-discovery is a process, not a skill that can be easily learned... Asking exploratory questions without implying interpretation is the most effective way to help the person being recalled put the underlying story into words so that the story becomes better known to him or her" [13:203].

The emphasis on remaining non-judgemental and trusting the Recaller's own process and experiencing suggests there is considerable overlap between IPR, PCA and the phenomenological method. Where Rogers formulated the conditions for personality change based on the relational qualities between therapist and client [25], Kagan based his IPR method on the potential for recall to deepen our awareness of our interpersonal processes [13], and Finlay describes the aim of phenomenological research in psychotherapy to give "insight into and understanding of the human condition. Sometimes it languages things we already know tacitly but have not articulated in depth. At other times quite surprising insights reveal themselves" [8:10]. What Finlay refers to here as 'tacit' knowledge overlaps with what Rogers might call congruence [25] and Kagan covert processes [13]. However, this paper does not primarily aim to theorise; rather it focuses on practiceled critical reflection in facilitating professions.

Tudor and Merry describe the person-centred approach to research as "characterised by a developing rather than pre-theorised mode of inquiry" [32:123].

Furthermore, they describe Rogers' theory of personality as "a phenomenological one as it is concerned with understanding individual perceptions of reality, indeed Spinelli refers to the PCA as 'clinical phenomenology' " [30:107]. This suggests the phenomenological method is consistent with adopting a person-centred approach to research. Both are essentially qualitative in nature and Creswell outlines the characteristics of qualitative research to include not only natural settings, but also an emphasis on participants' meanings, emergent design, reflexivity and holistic accounts, among others [7:186].

Furthermore McLeod compares qualitative research to psychotherapy in that the knowledge it generates is "holistic, nuanced, personal, contextualised, incomplete" [21:ix]. This resonates with our aim to produce 'comprehensive descriptions' of the phenomenon [23:177] and our wish to facilitate the exploration of each co-researcher's experiencing and awareness, and to synthesise these in a way that is inclusive and tolerant of ambiguity and contradiction. 
IPR and the phenomenological method make it possible to get close to the co-researcher's original experience both through recall, deepening their memory of that total experience, and through reflexivity. It is important that co-researchers retain their power in terms of what and how much they recall - consistent with the principles of IPR [13] - and in terms of describing the meaning of their experience - consistent not only with phenomenology [31] but also the PCA [26]. It is a shared characteristic of the PCA and of phenomenology that being takes precedence over knowing. In his discussion of a 'fully-functioning person', Rogers suggested "He will meet each situation with behaviour which is a unique and creative adaptation to the newness of that moment" [26:251].

\section{Doing IPR}

It is important to be transparent about the process for both ethical reasons (emotional and psychological safety) and practical reasons (to avoid confusion). Below is the outline the second author gives at the start of an IPR research methods workshop:

- Today we will video record each group working together

- Tomorrow we will invite each group to watch their own video playback and an 'inquirer' (researcher) will ask members of the group to pause the video whenever they recall thinking or feeling anything that they did not say

- Choose 5-10 minutes of video you would like to see again (this should be enough for 40-45 minutes recall)

- After the recall session, there will be time for a debrief (15-20 mins), where members of the group can reflect on the session and any self-learning that arose from it, and discuss any research questions

- I will analyse the data using a Phenomenological Method based on Spinelli [31], for possible

inclusion in research publications

Other research methods may be appropriate too - for example, Grounded Theory is also widely used with IPR in psychotherapy research [2].

It is useful to establish guidelines for co-researchers regarding the roles of Recaller and Inquirer in IPR:

\section{A brief outline of the Recaller's approach:}

- You are in control of playback and determine how far the exploration should go (wear headphones if you can and don't let Inquirer watch video)

- During the recall session, be as honest and as probing of yourself as you can

- Stop the recording as often as you can and explore the thoughts, feelings, physical sensations etc that were unspoken at the time

- Focus on the recording, not on the here-and-now (you will have an opportunity to reflect and explore implications in the debrief following the recall session)

- Try not to speculate on what you might have said or done differently

- The inquirer is not there to offer suggestions or to sit in judgement of you, but rather to share in your selfdiscovery process

A brief outline of the Inquirer's approach: 
- Start the session with the introduction quoted at the beginning of this paper ('IPR is about....')

- give attention to the recaller/s only, not to the recording (also better if you were not present at recording)

- exploratory, brief, open-ended questions in response to recaller's comments (see Inquiry Leads below)

- mixture of questions about thoughts and feelings

- listening and learning rather than feeling/interpreting/counselling/teaching

- non-judgemental, non-diverting

- focus on then (past tense) not now

- follow up prompts with appropriate next statements (eg What effect did that feeling have on you? Did you think s/he knew that you felt that? How? etc)

Some examples of Inquiry Leads include:

Kagan [13] based inquiry leads around themes such as: self-exploration, view of the other, own behaviour, values and assumptions, and hopes and intentions.

Some examples of Inquiry Leads include:

- What were you thinking?

- What were you feeling?

- What pictures, memories or words were going through your mind?

- Was there anything you wanted to say but couldn't find the 'appropriate' words for?

- Were you aware of any risks? Did you imagine the outcomes of anything you considered doing?
- Do you recall how your body felt? Can you recall any specific parts of your body reacting more than the other parts?

- Were you aware of any changes in your body at that time?

- Were there any physical sensations then? Where did you notice them most? When?

- If that physical sensation had a voice of its own, what would it have said?

Debrief After Recall:

- brings everyone back to the here-and-now after the session

- provides an opportunity to process and explore any thoughts and feelings that arose from recall

- opportunity to reflect in terms of practice, values, beliefs, self-discovery, and personal growth, and to discuss and explore research questions

- check everyone is feeling grounded and had opportunity to process any difficult emotional/psychological responses (if not, make arrangements for further contact/support)

\section{Ethical Considerations}

We base our ethical practice on the British Association for counselling and Psychotherapy (BACP) Ethical Framework [3]:

- Being Trustworthy: honouring the trust placed in the practitioner

It is our responsibility as a researcher to ensure that the environment is safe - emotionally and 
psychologically - so far as is possible. As a personcentred psychotherapist, this means offering Rogers' conditions [25] of empathic understanding and unconditional positive regard to the co-researcher, as well as being aware of our own state of congruence.

- Autonomy: Respect for the right to be self-governing

IPR as a method gives power to the Recaller not only in when to pause the recording, but in facilitating their self-discovery with appropriate prompts and follow-ups that seek to deepen self-awareness and selfunderstanding rather than to interpret or set an agenda. In this sense the research interview structurally underpins the co-researcher's autonomy not only in choosing which material to bring but also in exploring it.

- Beneficence: Commitment to promoting well-being

In addition to transparency about the IPR method, this builds in to the process a debrief for both client- and therapist-participants to ensure psychological safety in ending each section of the process.

\section{- Non-maleficence: Commitment to avoiding harm}

By ensuring that no-one other than the co-researcher themselves ever sees the video, which is destroyed immediately after the (audio-recorded) recall session and research interview that follows it.

- Justice: The fair and impartial treatment of all clients and the provision of adequate resources

In setting out detailed Information for co-researchers and Informed Consent and by following the procedures set out, we seek to be fair and impartial to all of the coresearchers. In addition to this, in our own interactions with co-researchers we seek to be transparent and supportive, being alert and responsive to their needs in the process.

\section{Implications for Participatory Design}

\section{Research}

It is useful to repeat here that the emphasis of this method is on the learning of the recaller about

themselves in the interaction, rather than the more usual behaviourist approach in design research, in which we seek to better understand the motivations, desires and needs of a user.

Of course, IPR is a flexible method that can be employed in this way; Macaskie et al have developed its use in such a way that the facilitator learns more accurately and comprehensively about the recaller [20]. Instrumental ways of working put the technology in the hands of the recaller, but interpretation and learning becomes the right of the inquirer; we can see similarities with some observational techniques in design research, such as Visual Ethnography [10], and even Cultural Probes [9], [11], where the material produced is returned to the research team for inspiration or analysis, often in the name of gathering requirements for systems development, without much attention paid to the socio-political implications of such systems [5]. As design research teams, we tend to

"shape our sensibilities, knowledge, and understanding of the fragments of life we study" [27:36], and "analyze and make sense of the visual output generated by the respondents" [24:553], seeing cultural self-portrayal as something that "needs to be verbally or visually framed within the research output" [24:553].

Fieldwork done in this way traditionally strives as far as possible to be objective and scientific, leaving the 
existing culture of practice undisturbed, and bracketing the cultural assumptions of the observer [10], [24]. The Person-Centred Approach, within which we are using IPR, takes a different view: that the interaction between the field and the observer needs to be acknowledged, and that both will be changed by the interaction. This is in contrast to behaviourist or psychoanalytical traditions used in the name of 'scientific' research $[24: 560,564]$ and, we hope, contributes to the efforts of design researchers developing cooperative analysis methodologies [6].

Here we want to emphasise IPR's value to a PersonCentred Approach to participatory design, in which the power remains with the recaller.

This apparently simple statement has significant implications for the participatory design research process. Many teams have reported on experiencing personal growth and change as they work together with particating communities [12], and some unpack the moments in which power is deliberately left with or given back to the participants as part of the process [19]. We discuss this aspect of power in relation to the Person-Centred Approach more fully in [15] and [17], but the IPR method foregrounds it unmistakably, because although as design researchers we have started to hand the technologies for reflection to our users, for the most part it feels unnatural to us to also relinquish the task of interpretation and analysis. Using IPR in this way throws into sharp relief the roles we habitually assume within the participatory process, and challenges us to become true participant observers, in a process with other participant observers, in a process with other participant observers. As such, although we might initially see IPR as more useful in reflecting on our own experiences within the design team, if the roles of all participants are equal, then it becomes a powerful tool for all co-researcher/co-

designers/participants. The heuristic paper, which accompanies this introduction, describes the ways we are using IPR as part of a multidisciplinary design research project with mental health service users in the UK [16].

\section{Acknowledgements}

We thank all the participants who took part in our pilot study in Nottingham in 2014, and the Bassetlaw Mind service users, staff and volunteers who contributed to the participatory design workshops in 2015. This work has been made possible through an EPSRC Researchin-the-Wild grant EP/L023601/1.

\section{References}

[1] Allen, P. The Use of Interpersonal Process Recall (IPR) in Person-Centred Supervision (2004). In K. Tudor and M. Worrall (Eds.). Freedom To Practice: Person-Centred Approaches to Supervision, PCCS Books, Ross-on-Wye, 2004, 153-170.

[2] Angus, L., Watson, J. C., Elliott, R., Schneider, K. and Timulak, L. Humanistic psychotherapy research 1990-2015: From methodological innovation to evidence-supported treatment outcomes and beyond.

Psychotherapy Research 25, 3 (2014), 1-18.

[3] BACP Ethical Guidelines for Researching Counselling and Psychotherapy.

http://www.bacp.co.uk/research/ethical guidelines.php [4] V. Ball. 1994. "Good Staff Sit Quietly": A Study of Primary Health Care Team Meetings. MSc Dissertation. University of Sheffield, UK.

[5] Richard Coyne. Designing Information Technology in the Postmodern Age. MIT Press, Cambridge, MA., 1995.

[6] Crabtree, A., Hemmings, T., Rodden, T.,

Chevherst, K., Clarke, K., Dewsbury, G., Hughes, J. and Rouncefield, M. Designing with care: adapting cultural 
probes to inform design in sensitive settings. Proc.OzCHI 2003, ACM Press (2003), 4-13.

[7] Creswell, J. W. Research Design. Sage, Thousand Oaks, 2014

[8] Finlay, L. Phenomenology for Therapists:

Researching the Lived World. Wiley-Blackwell, Chichester, 2011.

[9] Gaver, B., Dunne, T. and Pacenti, E. Cultural

Probes. Interactions 6, 1 (1999), 21-29.

[10] Harper, D. Framing photographic ethnography: a

case study. Ethnography 4, 2 (2003), 241-266.

[11] Hemmings, T., Clarke, K., Rouncefield, M.,

Crabtree, A. and Rodden, T. Probing the Probes. Proc PDC, ACM Press (2002), 42-50.

[12] Jurmu, M., Ylipulli, J. and Luusua, A. I've Had It! Group therapy for interdisciplinary researchers. Ext. Abstracts Critical Alternatives, (2015).

[13] Kagan, N. Interpersonal Process Recall: A Method for Influencing Human Interaction. Mason Media, Houston, TX, 1980.

[14] Kettley, R. What is the Person-Centred trainee therapist's awareness of their own body language and its possible impact on the therapeutic relationship? MSc dissertation. Sherwood Psychotherapy Training Institute, Nottingham, 2013.

[15] Kettley, S., Kettley, R. and Bates, M. An Introduction to the Person-Centred Approach as an Attitude for Participatory Design. Adjunct Proc. Ubicomp/ISWC'15, ACM Press (2015).

[16] Kettley, S., Bates, M. and Kettley, R. Reflections on the heuristic experiences of a multidisciplinary team trying to bring the PCA to Participatory Design (with emphasis on the IPR method). Adjunct Proc.

Ubicomp/ISWC'15, ACM Press (2015).

[17] Kettley, S., Kettley, R. and Lucas, R. Personalized or Person-Centred Design? In T. Fisher \& I. Kuksa (Eds.). Design for Personalisation. Gower, Farnham forthcoming.

[18] Larsen, D., Flesaker, K. and Stege, R. Qualitative Interviewing Using Interpersonal Process Recall: Investigating Internal Experiences during Professional-
Client Conversations. International Journal of Qualitative Methods 7, 1 (2008), 18-37.

[19] Light, A. and Akama, Y. Structuring Future Social Relations: The Politics of Care in Participatory Practice. Proc. PDC, ACM Press (2014), 151-160.

[20] Macaskie, J., Meekums, B. and Kapur, T. Reflective Methods in Counseling/Psychotherapy training: a scoping review of interpersonal process recall and reflecting team methods. BACP Conference, University of Nottingham, 2015.

[21] McLeod, J. Qualitative Research in Counselling and Psychotherapy. (2nd. ed.). Sage, London, 2011.

[22] Moncur, M. The emotional wellbeing of researchers: considerations for practice. Proc. CHI (2013), 18831890.

[23] Moustakas, C. Phenomenological Research Methods. Sage, London, 1994.

[24] Pauwels, L. Visual Sociology Reframed: An analytical synthesis and discussion of visual methods in social and cultural research. Sociological Methods \& Research, 38, 4 (2010), 545-581.

[25] Rogers, C. R. The Necessary and Sufficient Conditions of Therapeutic Personality Change (1957)

In $\mathrm{H}$. Kirschenbaum and V. L. Henderson (Eds.). The Carl Rogers Reader. Constable, London, 1990, 219235.

[26] Rogers, C. R. A Theory of Therapy, Personality and Interpersonal Relationships, as Developed in the ClientCentred Framework (1959). In H. Kirschenbaum and V. L. Henderson (Eds.). The Carl Rogers Reader. Constable, London, 1990, 236-257.

[27] Salvador, T., Bell, G. and Anderson, K. Design Ethnography. Design Management Journal, 10, 4 (1999), 35-41.

[28] Sanders, E. On Modeling: An Evolving Map of Design Practice and Design Research. ACM Interactions, $X V, 6$ (2008), 13-17.

[29] Sanders, P. History of CCT and PCA: Events, Dates and Ideas (2004). In P. Sanders (Ed.). The Tribes of the Person-Centred Nation, PCCS Books, Ross-on-Wye, 2004, 1-20. 
[30] Spinelli, E. The Interpreted World. London: Sage (1989). Cited by Tudor, K. and Merry, T. Dictionary of Person-Centred Psychology. PCCS Books, Ross-on-Wye, 2002.

[31] Spinelli, E. The Interpreted World: An Introduction

to Phenomenological Psychology. (2nd. ed.). Sage,

London, 2005.
[32] Tudor, K. and Merry, T. Dictionary of Person-

Centred Psychology. PCCS Books, Ross-on-Wye, 2002.

[33] Vines, J., Clarke, R., Wright, P, McCarthy, J. and

Olivier, P. Configuring Participation: On How We

Involve People In Design. Proc. CHI (2013), 429-438. 